\title{
Berberine inhibits p53-dependent cell growth through induction of apoptosis of prostate cancer cells
}

\author{
MYOUNG SUK CHOI ${ }^{1}$, JU HOON OH ${ }^{1}$, SUN MI KIM ${ }^{1}$, HAI YOUNG JUNG ${ }^{2}$, HWAN SOO YOO ${ }^{1}$, \\ YONG MOON LEE ${ }^{1}$, DONG CHEUL MOON ${ }^{1}$, SANG BAE HAN $^{1}$ and JIN TAE HONG ${ }^{1}$ \\ ${ }^{1}$ College of Pharmacy and MRC, and ${ }^{2}$ School of Life Science, Chungbuk National University 12 , \\ Gaeshin-dong, Heungduk-gu, Cheongju, Chungbuk 361-763, Korea
}

Received September 5, 2008; Accepted December 9, 2008

DOI: 10.3892/ijo_00000250

\begin{abstract}
Berberine has anti-tumor properties in some cancer cells including prostate cancer, but the exact mechanisms and in vivo effects are unclear. We investigated anti-cancer activity of berberine in vitro and in vivo, and possible mechanisms in prostate cancer cells. Berberine treatment inhibited cell cancer growth in a concentration $(0-50 \mu \mathrm{M})$ and time- $(0-$ $48 \mathrm{~h}$ ) dependent manner without any growth inhibition in normal human prostate epithelial PWR-1E cells. However, the p53 expressing LNCaP cells were more susceptible against berberine than the p53 lacking PC-3 cells. The cell arrest in $\mathrm{G}_{0} / \mathrm{G}_{1}$ phase, apoptotic cell death and the expression of apoptotic cell death proteins Bax and caspase-3 was much higher in berberine-treated LNCaP cells than those in PC-3 cells. Exploration of p53 siRNA or pifithrin- $\alpha$, a p53 inhibitor to the LNCaP cells, suppressed berberine-induced cell death and expression of apoptosis-related proteins. In xenograft in vivo studies, berberine reduced tumor weights and volumes accompanied with apoptotic cell death and increased expression of apoptotic cell death proteins, however, the extent of inhibitory effect was more significant in LNCaP cell-bearing mice. Therefore, these results indicated that berberine inhibited p53-dependent prostate cancer cell death.
\end{abstract}

\section{Introduction}

Chemoprevention, which refers to the administration of synthetic or natural agents to prevent the initiation and/or promotional events associated with carcinogenesis, is being increasingly appreciated as an attractive approach for the management of cancer development (1). In recent years, apoptosis has come to be a good way to eliminate pre-

Correspondence to: Dr Jin Tae Hong, College of Pharmacy and MRC, Chungbuk National University, 12 Gaeshin-dong, Heungduk-gu, Cheongju, Chungbuk 361-763, Korea

E-mail: jinthong@chungbuk.ac.kr

Key words: berberine, p53, apoptosis, prostate cancer cells cancerous and/or cancer cells (2,3). Thus, chemopreventive agents that can modulate apoptosis may be able to affect the steady-state cell population, which may be useful in the management and therapy of cancer development. Many natural compounds inducing apoptosis have been developed as preventive and/or treatment agents of cancer development $(4,5)$.

Berberine is an isoquinoline alkaloid that has been isolated from Hydrastis canadensis (goldenseal), Coptis chinensis (Coptis or goldenthread), Berberis aquifolium (Oregon grape), Berberis vulgaris (barberry), and Berberis aristata (tree turmeric). Berberine possesses a wide range of biochemical and pharmacological activities such as, anti-diarrheal (6), anti-arrhythmic (7), and anti-inflammatory (8) activity. Berberine has been examined for anti-cancer activity following evidence of anti-neoplastic properties $(9,10)$. Berberine has been shown to inhibit effectively human colon cancer cell growth by inhibiting cyclooxygenase- 2 transcriptional activity (11), arylamine $\mathrm{N}$-acetyltransferase activity (12), and DNA topoisomerase I and II (13), and by acting intercalating agent $(14,15)$. Therefore, it is possible that berberine may have anti-cancer activities through multiple anti-cancer mechanisms depending on the cell type and status (16).

p53, a tumor suppressor protein, serves as the major obstruction for carcinogenesis. Indeed, approximately 50\% of human cancers bear p53 gene mutations (17). p53 is activated as a transcription factor in response to e.g., oncogene activation, hypoxia and DNA damage, resulting in growth arrest and/or apoptosis by stimulating the expression of various p53 target genes such as $p 21^{\text {WAFI/CIPI }}$, Bax, Puma, Noxa, Apaf-1, Fas, and DR5 $(18,19)$. p53 can also transcriptionally repress the expression of anti-apoptotic proteins, e.g., Bcl-2, Bcl-XL or survivin (20). Bax gene product dimerizes with Bcl-2 and prevents the activity of Bcl-2 from blocking apoptosis (21). The Bax protein controls cell death through activation of caspases-9 and -3 (22). Several natural compounds such as curcumin (23), resveratrol (24), (-)Epigallocatechin-3-gallate (EGCG) (25), capsaicin (26) and glycolic acid (27) have been reported to induce p53dependent apoptosis in human ovarian, liver, prostate, leukemic and keratinocyte cancer cells. We recently found that berberine induced p53-dependent apoptosis of neuroblastoma cells (unpublished data). 
In the present study, we investigated the inhibitory effects of berberine on human prostate cancer cell growth via apoptotic cell death, and whether berberine-induced apoptosis is p53-dependent in prostate cancer LNCaP (p53 expressing) and PC-3 (p53 lacking) cells in in vitro and in vivo.

\section{Materials and methods}

Cell culture and treatment. Human prostate cancer LNCaP cells, PC-3 cells, and the non-neoplastic human prostate epithelial cell line PWR-1E were purchased from the American Type Culture Collection (Manassas, VA, USA). The prostate cancer cell lines were cultured in RPMI-1640 supplemented with $10 \% \mathrm{FBS}, 100 \mathrm{mg} / \mathrm{ml}$ penicillin-streptomycin and maintained in an incubator with a humidified atmosphere $5 \% \mathrm{CO}_{2}$ at $37^{\circ} \mathrm{C}$. The PWR-1E cells were cultured in keratinocyte growth medium supplemented with $5 \mathrm{ng} / \mathrm{ml}$ human recombinant epidermal growth factor and $0.05 \mathrm{mg} / \mathrm{ml}$ bovine pituitary extract (Gibco/Invitrogen, Carlsbad, CA, USA). Berberine was purchased from Sigma Aldrich (St. Louis, MO, USA). In all treatment, berberine was dissolved in dimethyl sulfoxide (DMSO) and made up to the maximum final concentration of $0.05 \%(\mathrm{v} / \mathrm{v})$ in the complete cell culture medium.

p53 siRNA transfection. Sequences of oligonucleotides of p53 siRNA were purchased from Samchully Pharm. Co. (Seoul, Korea). The sequence of the p53 oligonucleotide is: sense 5'(CUACUUCCUGAAAACAACG)d(TT)3' and antisense 5'(CGUUGUUUUCAGGAAGUAG)d(TT)3'. siRNA oligonucleotides were transfected using the siPORT ${ }^{\mathrm{TM}}$ $\mathrm{NeoFX}^{\mathrm{TM}}$ (Ambion, Cambridgeshire, UK). In preliminary studies, cells were treated with $10-200 \mathrm{nM}$ of p53 siRNA according to the manufacturer's instructions in order to determine the optimum concentration to down-regulate the target genes. In later studies, cells were transfected with 10 , 50 , and $100 \mathrm{nM}$ siRNA for $4 \mathrm{~h}$, and then the cell were grown for a further $48 \mathrm{~h}$ in normal medium. The effect of siRNA treatment on sensitivity to apoptosis was assessed by flow cytometry $48 \mathrm{~h}$ after berberine treatment. The effect on cell viability of p53 siRNA treatment was determined by cell viability test 24 and $48 \mathrm{~h}$ after berberine treatment. Treatment of cells with the selective p53 inhibitor, pifithrin- $\alpha$ (Calbiochem, CA), was performed by pretreatment the cells with the inhibitor $24 \mathrm{~h}$ prior to addition of berberine.

Cell viability assay. Cell viability assay was performed as described previously (28). Cells were plated in 96-well plates, and subconfluent cells were subsequently treated with berberine $(0,5,10,20$, and $50 \mu \mathrm{M})$ for 24,48 , and $72 \mathrm{~h}$. After treatment, cell viability was measured by Cell Counting Kit- 8 (CCK-8) system according to the manufacturer's instructions (Dojindo, Kumamoto, Japan).

Cell cycle analysis by flow cytometry. Subconfluent cells were treated with berberine $(0,5,10,20$, and $50 \mu \mathrm{M})$ in culture medium for $48 \mathrm{~h}$ and $50 \mu \mathrm{M}$ concentration of berberine in complete medium for $0,6,12,24,48$, and $72 \mathrm{~h}$. Flow cytometric analysis was done as previously described
(28). The cell cycle distribution was determined using a FACSCalibur instrument (BD Biosciences, San Jose, CA).

Apoptosis evaluation. Apoptosis assays were carried out in the berberine treated cells by using flow cytometric analysis and by observing fluorescence microscopy after the terminal nucleotidyl transferase-mediated nick end-labeling (TUNEL) method using the In Situ Cell Death Detection Kit (Roche Diagnostics GmbH, Mannheim, Germany) according to the manufacturer's instructions. The cells were then observed through a fluorescence microscope (magnification x400, Leica Microsystems AG, Wetzlar, Germany). TUNEL staining assay as previously described (28).

Immunofluorescence staining. Immunofluorescence staining was done as described previously (28). The cells were cultured with medium containing berberine $(10$ and $50 \mu \mathrm{M})$ or vehicle for $48 \mathrm{~h}$. Primary polyclonal antibodies for p53 (1:400 dilution) and anti-rabbit-biotinylated secondary antibodies Alexa Fluor 568 (Molecular Probes Inc., Eugene, OR) (1:200 dilution) were used. Upon nuclear stain and mount in antifade medium with DAPI (Vector Laboratories, Inc.), immunofluorescence images were acquired using a confocal laser scanning microscope (TCS SP2; Leica Microsystems AG) equipped with a 630x oil immersion objective.

Western blot analysis. Western blot analysis was done as described previously (28). The cells were harvested and homogenized in lysis buffer Pro-Prep (iNtRON Biotechnology Co., GyeongGi-do, Korea). The membrane was immunoblotted with primary specific antibody: mouse monoclonal antibodies against CDK2, CDK4, cyclin D1, cyclin E and p21 (1:1000 dilution, Medical \& Biological Laboratories Co., Ltd., Nagoya, Japan), rabbit polyclonal for p53, Bax (1:500 dilution, Santa Cruz Biotechnology Inc. Santa Cruz, CA, USA), Bcl-2, PARP and cleaved caspase-3 (1:1000 dilution, Cell Signaling Technolology, Inc. Beverly, MA, USA). The blot was then incubated with the corresponding conjugated anti-mouse and anti-rabbit immunoglobulin G-horseradish peroxidase (1:4000 dilution, Santa Cruz Biotechnology Inc.). Immunoreactive proteins were detected with the ECL Western blotting detection system. The relative density of the protein bands was scanned by densitometry using MyImage (SLB, Seoul, Korea) and quantified by Labworks 4.0 software (UVP Inc., Upland, CA). The tumor fragments were homogenized in lysis buffer Pro-Prep, and then, equal amounts of proteins $(80 \mu \mathrm{g})$ were studied under the same conditions and course.

Anti-tumor activity of berberine in vivo xenograft. Six-weekold male BALB/c athymic nude mice were purchased from Japan SLC (Hamamatsu, Japan). Prostate cancer PC-3 and LNCaP cells were injected subcutaneously $\left(1 \times 10^{7}\right.$ tumor cells/0.1 ml PBS/animals) with a 27 -gauge needle into the right lower flanks of the mice. Tumors were removed from mice, and same size tumor fragments $(3 \times 3 \times 3 \mathrm{~mm})$ were then implanted s.c. into the right flank of other BALB/c athymic nude mice with a 13-gauge trocar needle. When the tumors had reached an average volume of $\sim 100-300 \mathrm{~mm}^{3}$, the tumorbearing nude mice were intraperitoneally injected with 
A

B

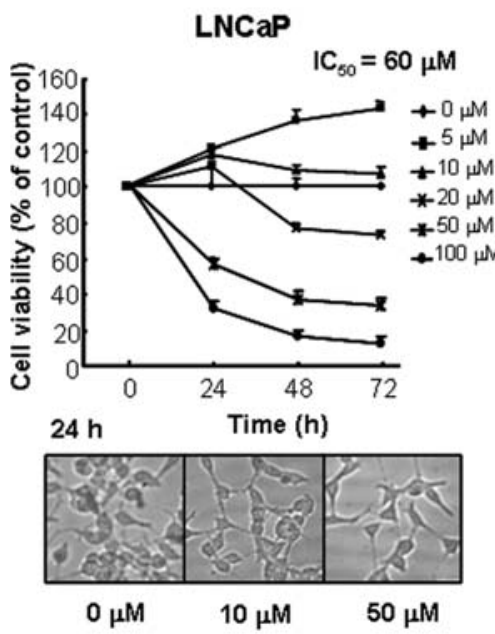<smiles>COc1ccc2cc3[n+](cc2c1OC)CCc1cc2c(cc1-3)OCO2</smiles>
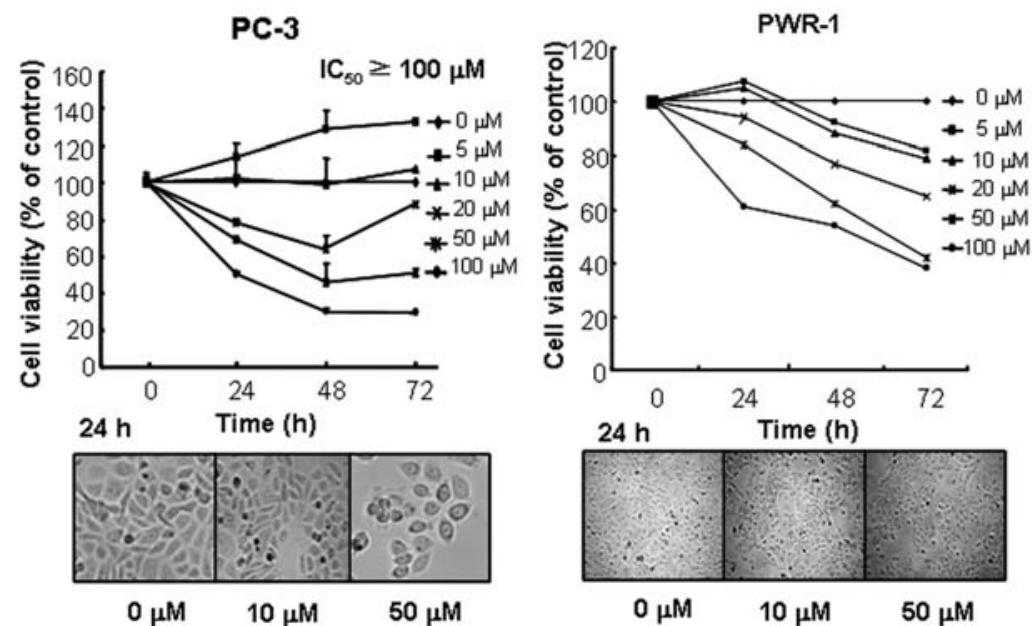

Figure 1. Effect of berberine on cell viability in human prostate cancer cells. (A) Chemical structure of berberine. (B) Concentration- and time-dependent effect of berberine on the cell viability. As detailed in Materials and methods, the cells were treated with berberine (5-100 $\mu \mathrm{M})$ for 24,48 , and $72 \mathrm{~h}$, and their viability was determined by CCK-8 kit. The data are expressed by the percent of control cells (without the berberine treatment) as the mean \pm SD of 3 experiments with replicates. After $24 \mathrm{~h}$ of berberine treatment, the cells morphologic change was observed under phase contrast microscope (magnification $\mathrm{x} 200)$.

berberine ( 5 and $10 \mathrm{mg} / \mathrm{kg}$, twice per week for 4 weeks). The group treated with saline was used as the control. The weight and tumor volume of the animals were monitored once per week. The tumor volumes were measured with vernier calipers and calculated by the following formula: $\left(\mathrm{A} \mathrm{x} \mathrm{B}^{2}\right) / 2$, where $\mathrm{A}$ is the larger and $\mathrm{B}$ is the smaller of the 2 dimensions of the tumor. At the end of the experiment, the animals were sacrificed with cervical dislocation. The tumors were separated from the surrounding muscles and dermis, excised and weighed.

Immunohistochemistry. All specimens were fixed in formalin and paraffin-enclosed for examination. Sections 5- $\mu$ m thick were stained with hematoxylin and eosin (H\&E) and immunohistochemistry for proliferating cell nuclear antigen (PCNA) and cleaved caspase-3. Paraffin-embedded sections were deparaffinized in xylene, rehydrated through graded alcohols to water, and then incubated for $10 \mathrm{~min}$ in PBS. The endogenous peroxidase was inactivated by incubation for $10 \mathrm{~min}$ in $3 \%$ peroxide in methanol and rehydrated for $10 \mathrm{~min}$ in PBS. The sections were blocked for $30 \mathrm{~min}$ with $3 \%$ normal horse serum diluted in PBS; the sections were then blotted and incubated with primary mouse anti-human PCNA monoclonal antibody (Santa Cruz Biotech) for $4 \mathrm{~h}$ at room themperature and primary rabbit anti-cleaved caspase- 3 antibodies (Cell Signaling Tech, Danvers, MA) for overnight at $4^{\circ} \mathrm{C}$. The slides were incubated with biotinylated horse antibody for $2 \mathrm{~h}$ and washed in PBS, followed by the avidin- biotin-peroxidase complex (ABC, Vector Laboratories, Inc., Burlingame, $\mathrm{CA}$ ). The slides were washed and the peroxidase reaction developed with diaminobenzidine and peroxide, then counterstained with hematoxylin, mounted in aqua-mount, and evaluated by light microscopy. A negative control was performed in all cases by omitting the primary antibody.

\section{Results}

Effect of berberine on cell growth in prostate cancer cells. Berberine chloride shown in Fig. 1A, was studied to assess the inhibitory effect of berberine on cell growth of prostate cancer cells LNCaP and PC-3 cells, as well as normal human prostate epithelial cells (PWR-1E). The cells were treated with varying concentrations of berberine $(0,5,10,20,50$, and $100 \mu \mathrm{M}$ ) for 24,48 , and $72 \mathrm{~h}$. Berberine inhibits cell proliferation in prostate cancer cells at the concentration between 30 to $100 \mu \mathrm{M}$ in a concentration- and time-dependent manner. However, the wild-type p53 expressed LNCaP cells $\left(\mathrm{IC}_{50}=60 \mu \mathrm{M}\right)$ were more susceptible against berberine than that of the cells PC-3 $\left(\mathrm{IC}_{50} \geq 100 \mu \mathrm{M}\right)$ lacking p53. In contrast to the effect of berberine in cancer cell lines, nonneoplastic human prostate epithelial cells (PWR-1E) were not affected by these concentrations of berberine.

Berberine induces $G_{0} / G_{1}$-phase cell cycle arrest and decreases the levels of $G_{0} / G_{1}$ regulatory proteins. We determined the possible inhibitory effect of berberine on cell cycle progression 
A

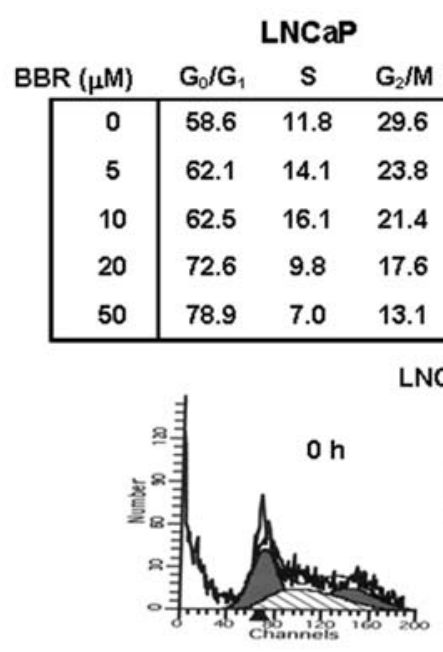

B

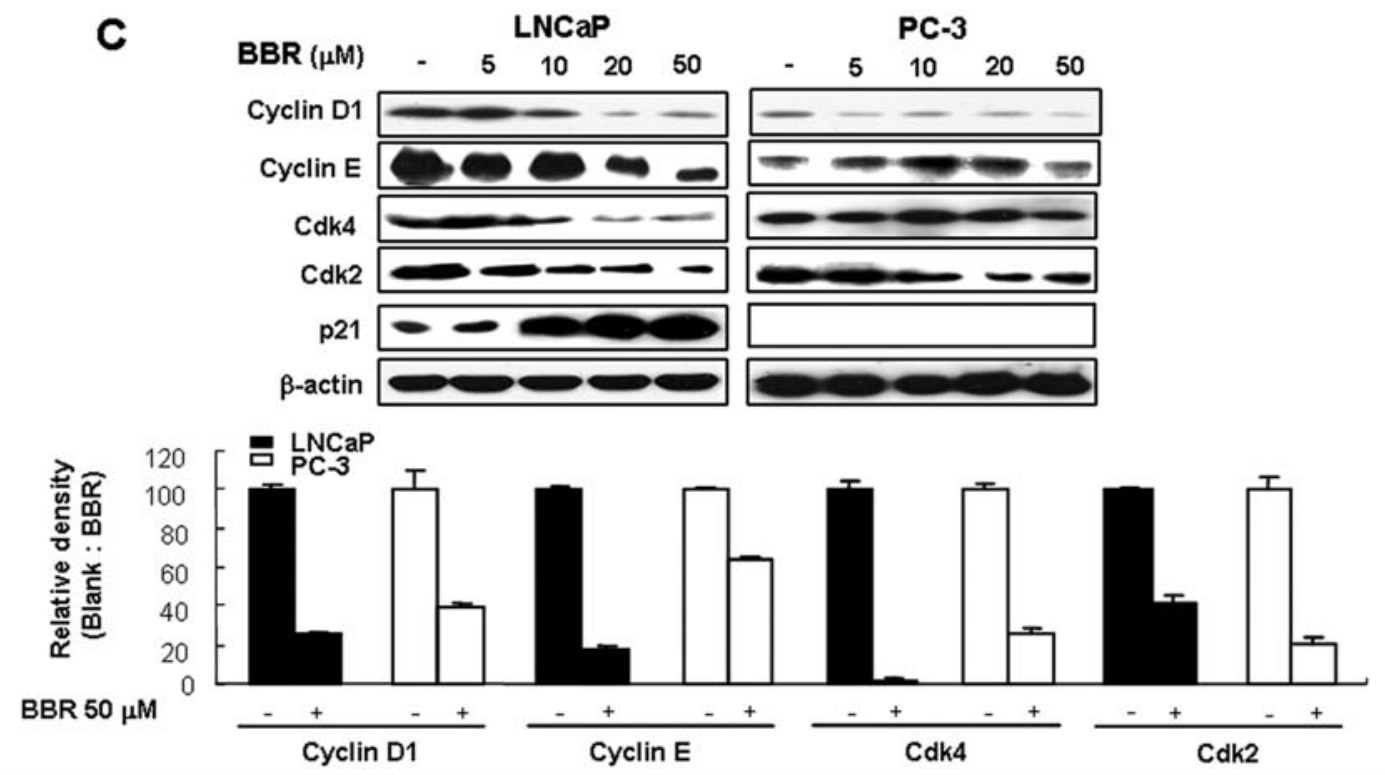

Figure 2. Effect of berberine on cell cycle progression and cell cycle regulatory proteins expression in human prostate cancer cells. (A) Concentrationdependent cell cycle progression. The cells were treated with $0,5,10,20$, and $50 \mu \mathrm{M}$ of berberine in complete medium. After $48 \mathrm{~h}$ of treatment, cells were harvested and digested with RNase A. Cellular DNA was stained with propidium iodide (PI) and flow cytometric analysis was performed to analyze the cell cycle distribution as detailed in Materials and methods. (B) Time-dependent cell cycle progression. The cells were treated with $50 \mu \mathrm{M}$ concentration of berberine in complete medium for $0,6,12,24,48$, and $72 \mathrm{~h}$. After various times of treatment, cells were harvested and analyzed for DNA content by PI staining. Similar results were obtained from three independent experiments. (C) Effect of berberine on the expression of cell cycle-related proteins (cyclins, Cdks, and p21) was determined using Western blot analysis. The cells were treated with or without berberine for $24 \mathrm{~h}$. Total cell lysates were processed for Western blot analysis as described in Materials and methods. B-actin was used as an internal control. The relative density was analyzed by densitometry. The data are expressed as the mean $\pm \mathrm{SD}$ of 3 experiments with replicates.

to investigate cell growth property of berberine. As summarized in Fig. 2, compared with vehicle treatment, berberine treatment resulted in a significantly higher number of cells in the $\mathrm{G}_{0} / \mathrm{G}_{1}$ phase in a concentration- and time-dependent manner (Fig. 2A and B). The number of cells at $\mathrm{G}_{2} / \mathrm{M}$ and $\mathrm{S}$ phase was also decreased in the two cell lines treated with increasing concentrations of berberine. After $6 \mathrm{~h}$ of treatment, the $G_{0} / G_{1}$ phase of cells gradually increased by the treatment of berberine up to $72 \mathrm{~h}$. It is noteworthy that treatment of berberine $(50 \mu \mathrm{M})$ for $48 \mathrm{~h}$ resulted in a significantly higher number of cells in the $\mathrm{G}_{1}$ phase in LNCaP (78\%), compared with those of PC-3 (66\%) cells.
These data suggest that inhibition of cell proliferation in prostate cancer cells by berberine may be associated with the induction of $\mathrm{G}_{0} / \mathrm{G}_{1}$ arrest.

The effect of berberine on cell cycle-regulatory molecules operative in $\mathrm{G}_{0} / \mathrm{G}_{1}$ phase of the cell cycle were then determined. In order to investigate the role of cyclin/Cdk complexes in the anti-proliferative activity of berberine, the expression of $\mathrm{G}_{0} / \mathrm{G}_{1}$ regulators cyclin $\mathrm{D} 1$, cyclin $\mathrm{E}, \mathrm{Cdk} 2$, and $\mathrm{Cdk} 4$ were analyzed in prostate cancer cells. Protein extracts were prepared from cells treated with varying concentrations of berberine for $24 \mathrm{~h}$. The treatment with berberine resulted in a significant reduction in cyclin D1, cyclin E, Cdk2, and Cdk4 
protein expression in both cell lines. The inhibition on the expression of $\mathrm{G}_{0} / \mathrm{G}_{1}$ regulatory protein in $\mathrm{p} 53$ expressed cells were much greater than that of p53 lacking cells (Fig. 2C). CDKIs are well known to interfere with cell cycle progression to cause phase-specific cycle arrest. Thus, the protein level of certain CDKI family member, such as p21, a crucial protein in the regulation of $\mathrm{G}_{1}$-phase progression, was determined by Western blot analysis. Berberine treatment upregulated the expression levels of p21 in LNCaP cells (Fig. 2C). However, p21 protein was not detected in PC-3 cells. These results imply that the down-regulation of cyclin D1, cyclin E, Cdk2, and Cdk4 protein expressions may be responsible for the $\mathrm{G}_{0} / \mathrm{G}_{1}$ cell cycle arrest induced by berberine, and regulation of $\mathrm{p} 21$ proteins may also be involved in berberine-triggered p53-dependent arrest of cells in $\mathrm{G}_{0} / \mathrm{G}_{1}$ phase of cell cycle.

Berberine induces apoptosis through mediation of apoptotic protein expression. To assess whether cell cycle arrest resulted in the induction of apoptosis flow cytometric analysis was used to quantify the prostate cancer cells. The cells were treated with varying concentrations of berberine $(0,5,10$, 20 , and $50 \mu \mathrm{M}$ ) for $48 \mathrm{~h}$. The treatment of LNCaP and PC-3 cells with berberine resulted in increasing apoptosis in a concentration-dependent manner (Fig. 3A). Consistent with results of cell viability test and cell cycle arrest, berberine induced more apoptosis in wild-type p53 expressing cells LNCaP $(88.5 \%)$ than in cells PC-3 (40.2\%) lacking p53 after treatment of $50 \mu \mathrm{M}$ of berberine. The increase in the percentage of apoptotic cells by berberine was further confirmed by using confocal microscopy after DAPI and TUNEL staining. As shown in Fig. 3B, DAPI-positive/ TUNEL staining cells were observed over a period of $48-\mathrm{h}$ exposure to berberine.

Since Bax and Bcl-2 plays a crucial role in apoptosis controlled by $\mathrm{p} 53$, we next determined the effect of berberine treatment of two cell lines on the levels of Bax and Bcl-2 expression. The Western blot analysis exhibited a significant increase in the protein expression of pro-apoptotic Bax (Fig. $3 \mathrm{C})$. In contrast, the expression of anti-apoptotic protein Bcl-2 was significantly decreased by berberine treatment in a concentration-dependent manner. Alteration in Bax/Bcl-2 is known to initiate caspase signaling, therefore, the involvement of cleaved caspase-3 during berberine-mediated apoptotic death was also investigated. As shown by the immunoblot analysis, berberine treatment resulted in a significant increase of the expression of cleaved caspase- 3 and PARP cleavage in a concentration-dependent manner. However, the extent of expression changes in the expression of Bax/Bcl-2 and cleaved caspase-3 was more significant in LNCaP cells than PC-3 cells (Fig. 3C).

Berberine induces p53 translocation to nucleus in LNCaP cells. p53 is a cellular gatekeeper for the cell growth and division (29). It has been shown that p53 can regulate cell cycle arrest, apoptosis, and DNA repair in a variety of cells. Since berberine induced more susceptibility to cells following apoptotic cell death in wild-type p53 expressing LNCaP cells, the effect of berberine on the p53 translocation into nuclear was investigated to see whether translocation of p53 into nuclear is implicated in regulation of gene expression. Cells were treated with berberine for $24 \mathrm{~h}$ and subjected to immunoblot analysis (Fig. 4A) and confocal microscopy (Fig. 4B). As shown in Fig. 4A, nuclear translocation of p53 proteins was highly increased in LNCaP cells in a concentration-dependent manner, but not in PC-3 cells. To further study the localization of p53 protein, the cancer cells were subjected to confocal microscopy by immunofluorescent staining of p53. As shown in Fig. 4B, the intensity of red fluorescence (Alexa 568) exhibiting p53 expression was significantly increased when exposed to $50 \mu \mathrm{M}$ berberine for $24 \mathrm{~h}$ in $\mathrm{LNCaP}$ cells. The increased p53 proteins were concentrated on the nuclei of these cells.

Knockdown of p53 decreases berberine-induced cytotoxicity and expression of apoptosis-related proteins in LNCaP cells. To further investigate whether berberine-induced apoptosis of cancer cells is p53-dependent or not, two sets of experiments were done. First, LNCaP cells were knocked down of p53 protein expression by p53 siRNA treatment. Second, LNCaP cells were treated with berberine in the presence and absence of PFT- $\alpha$, a compound that inhibits the accumulation and/or the transcriptional activity of p53 (30). The levels of cell viability, apoptotic cell death, and apoptotic protein expression in berberine-treated $\mathrm{LNCaP}$ cells were determined. As shown in Fig. 5Aa, transfection of p53 siRNA significantly reversed berberine-induced cell growth inhibition. Similarly, $24 \mathrm{~h}$ prior pretreatment of PFT- $\alpha$ (10 and $30 \mu \mathrm{M})$ also reversed the berberine-induced cell growth inhibition in LNCaP cells in a concentrationdependent manner (Fig. 5Ba). Furthermore, increase of the number of apoptotic cells by berberine was also reduced when cultures were treated with a combination of berberine and p53 siRNA/or PFT- $\alpha$ (Fig. 5Ab and 5Bb). In agreement with these findings, the expression of p53 and cleaved caspase- 3 protein in cells treated with a combination of berberine and $\mathrm{p} 53$ siRNA/or PFT- $\alpha$ reversed berberine induced expression (Fig. 5Ac and $5 \mathrm{Bc}$ ). These results demonstrate that berberine-induced apoptosis and inhibition of cell growth could be related with the activation of p53 signaling pathway.

Berberine inhibits growth of prostate cancer cells in vivo xenograft. To elucidate the anti-cancer effect of berberine in vivo, the tumor growth on prostate xenograft-bearing nude mice following berberine treatments was investigated. In xenograft studies, berberine was administrated intraperitoneally twice per week for 4 weeks to mice with tumors ranging from 100 to $300 \mathrm{~mm}^{3}$. The body weight increase and hair coats as well as other overall behavioral activities were similar in the all group at the completion of the experiments, suggesting that berberine did not have major side effects on these mice (data not shown). Tumor volume was measured weekly, and all mice were sacrificed at the end of 4 week when tumors were dissected and weighted. The effect of berberine on growth of prostate cancer cells was significant in both xenograft model mice. Fig. 6A represents the relative tumor growth measured after treatment of berberine ( 5 and 10 $\mathrm{mg} / \mathrm{kg}, \mathrm{n}=10)$ and cisplatin $(5 \mathrm{mg} / \mathrm{kg}, 5$ times, $\mathrm{n}=5)$ in comparison with the sham control group (saline, $n=10$ ). 
A

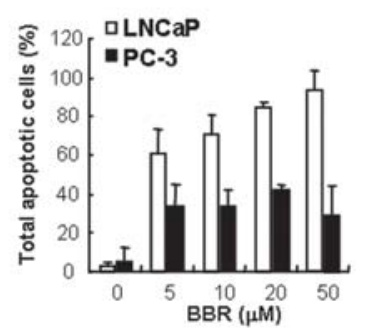

B

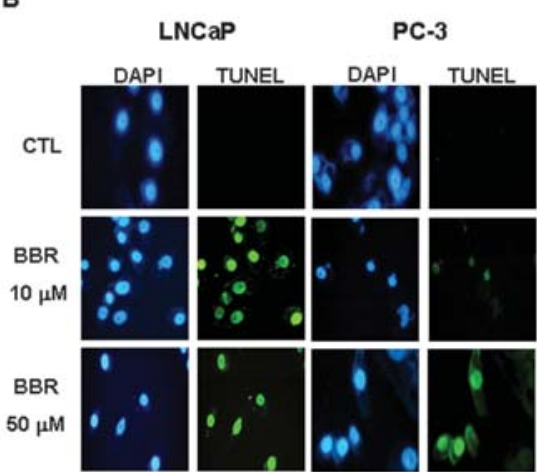

C

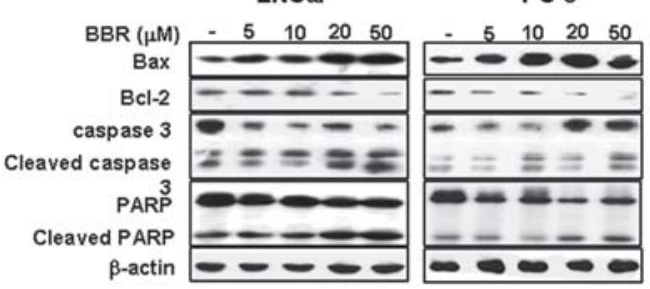

Figure 3. Effect of berberine on apoptosis and expression of apoptotic proteins in human prostate cancer cells. (A) Quantification of apoptosis by flow cytometric analysis. The cells were treated with berberine $0,5,10,20$, and $50 \mu \mathrm{M}$ for $48 \mathrm{~h}$, and then labeled TUNEL solution. (B) The green color in the fixed cells marks TUNEL-labeled cells. Total number of apoptotic cells in a given area was determined with DAPI nuclear staining TUNEL-labeled cells (magnification $\mathrm{x} 400$ ). The data are expressed as the mean \pm SD of 3 experiments. (C) Effect of berberine on the expression of apoptosis regulatory molecules (Bax, Bcl-2, caspase-3, and PARP) was determined using Western blot analysis. The cells were treated with various concentration of berberine for $24 \mathrm{~h}$. As detailed in Materials and methods, the total cell lysates were prepared for Western blot analysis. The relative density was analyzed by densitometry. The data are expressed as the mean $\pm \mathrm{SD}$ of 3 experiments.

\section{A}

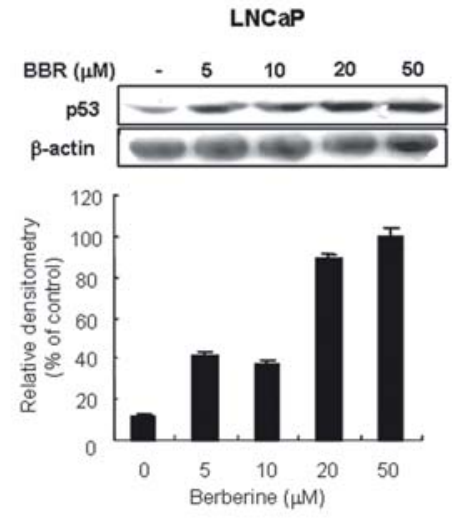

B

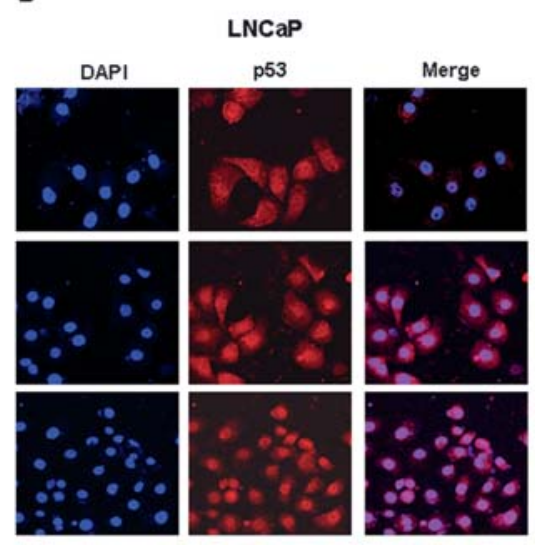

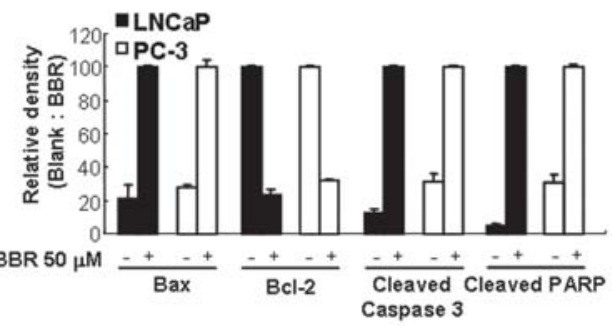

BBR $50 \mu \mathrm{M} \frac{-+-+}{\text { Bax }} \frac{-+-+}{\text { Bcl-2 }} \frac{-+-+}{\begin{array}{c}\text { Cleaved Cleaved PARP } \\ \text { Caspase 3 }\end{array}}$ 
A

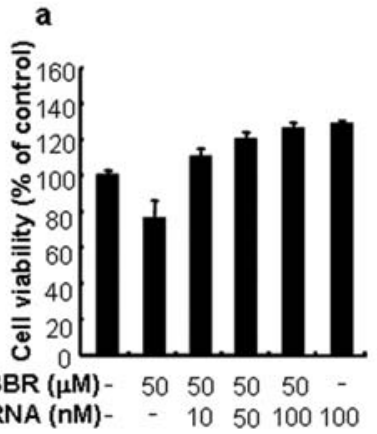

b

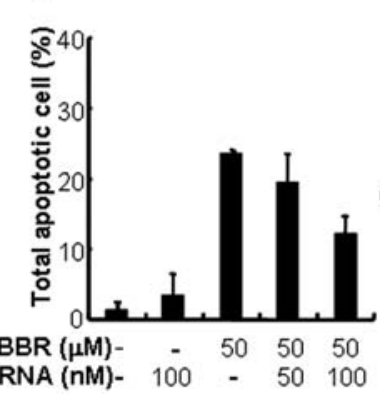

c

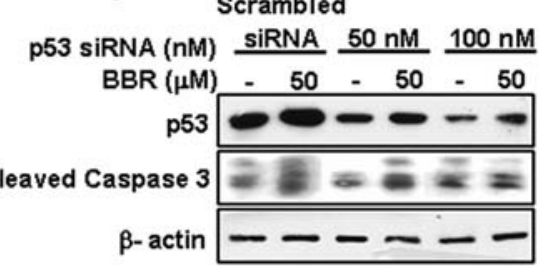

B

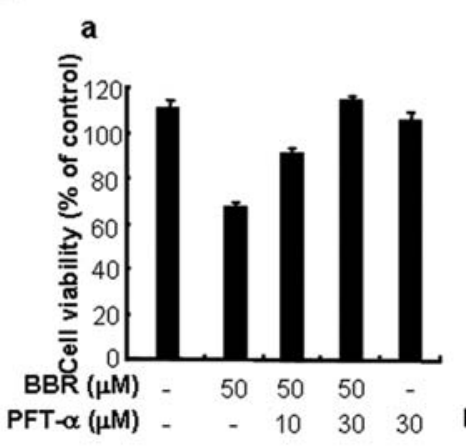

b

c

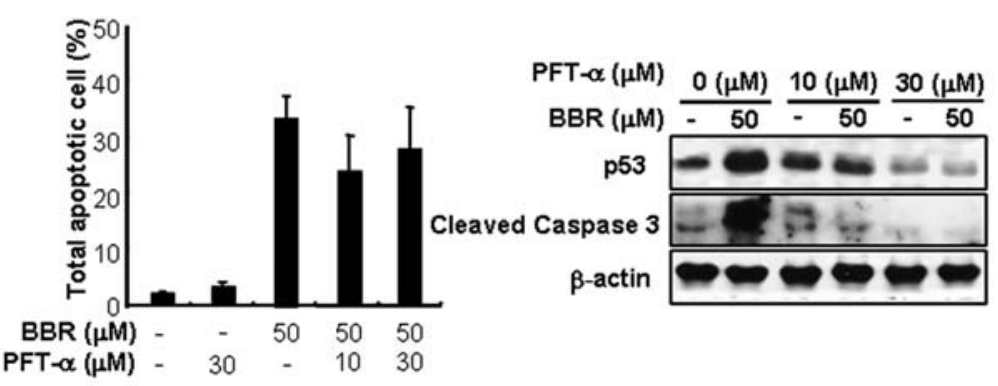

Figure 5. Effect of a p53 inhibitor or a p53 siRNA on the cell viability and apoptotic cell death in berberine-treated LNCaP cells. Suppressive effect of p53 siRNA and pifithrin- $\alpha$ treatment on the berberine-induced cancer cell growth inhibition, apoptosis, and expression of apoptotic regulatory proteins. (A) Cell viability (a) and apoptosis (b) in LNCaP cells transfected with p53 siRNA. The cells transfected with p53 siRNA for $4 \mathrm{~h}$, and the cell were grown for a further $48 \mathrm{~h}$ in normal medium, and then the cells were treated with berberine for $24 \mathrm{~h}$. (B) Cell viability (a) and apoptosis (b) in the LNCaP cells treated with p53 inhibitor (PFT- $\alpha$ ). The data are expressed in terms of percent of control cells (scrambled siRNA transfected cells) as the mean \pm SD of three experiments. Cell viability was determined by the CCK-8 kit. Quantification of apoptosis was determined by DAPI and TUNEL double staining assay. The data are expressed by the percent of control cells (without the berberine treatment) as the mean $\pm \mathrm{SD}$ of 3 replicates. Expression of apoptotic proteins was determined by Western blotting in LNCaP cells transfected with p53 siRNA (Ac) and PFT- $\alpha$ (Bc). Using the same protocol as for (A) and (B). Western blot analysis to detect the changes in p53 and cleaved caspase-3 protein expression levels. Similar results were obtained in three independent experiments.

Tumor growth was gradually and time-dependently retarded by the treatment of berberine. Tumor volumes in $10 \mathrm{mg} / \mathrm{kg}$ berberine-treated mice compared with those saline-treated were statistically significantly smaller $(1899.34 \pm 55.15$ versus $1255.62 \pm 50.18 \mathrm{~mm}^{3}$ and $1537.66 \pm 36.38$ versus $\left.984.38 \pm 50.68\right)$ in PC-3 and LNCaP bearing mice, respectively (Fig. 6A). Prostate tumor weights were significantly less in $10 \mathrm{mg} / \mathrm{kg}$ berberine-treated mice compared with that of saline-treated mice $(1.24 \pm 0.03$ versus $0.87 \pm 0.09$ in PC-3, and $1.19 \pm 0.04$ versus $0.55 \pm 0.05$ in $\mathrm{LNCaP}$ bearing mice), respectively (Fig. 6B).

The immunohistochemistry analysis of tumor section for hematoxylin and eosin revealed that berberine concentrationdependently inhibited tumor size and proliferation (Fig. 6C). We next determined the effect of berberine on the levels of cell proliferation marker PCNA, as well as apoptosis regulatory proteins, cleaved caspase-3. Using the expression of cleaved caspase-3, we confirmed that apoptosis-regulatory protein expression was significantly increased in berberine-treatment concentration-dependently in $\mathrm{LNCaP}$ and $\mathrm{PC}$-3-bearing mice. However, the extent of expression was more significant in LNCaP-bearing mouse tumors. Consistent with the immunohistochemistry data, the expression of cleaved caspase-3, and cleaved PARP detected with Western blotting in mice treated with $10 \mathrm{mg} / \mathrm{kg}$ of berberine were significantly increased compared to the control group, and the extent of change of these gene expressions were greater in LNCaP bearing tumor (Fig. 6D).

\section{Discussion}

In this study, we demonstrated that berberine (5-50 $\mu \mathrm{M})$ inhibited cancer cell growth in prostate carcinoma $\mathrm{LNCaP}$ and PC-3 cells through induction of apoptosis in vitro as well as in vivo xenograft model. Moreover, we also demonstrated that LNCaP, p53 positive cells, are more vulnerable to berberine, suggesting that activation of $\mathrm{p} 53$-dependent apoptosis pathway is involved in berberine-induced prostate cancer cell growth inhibition. Similar to our finding, previous other reports have demonstrated that berberine $(25-200 \mu \mathrm{M})$ inhibited human gastric carcinoma SNU-5 cells (31) and colon cancer cell growth (11) in vitro. Moreover, several studies have reported that berberine (15-75 and $10-100 \mu \mathrm{M}$ respectively) also induced apoptosis of human epidermoid carcinoma A431 cells and prostate cancer cells (DU145, PC-3, and LNCaP) $(32,33)$. Letasiova et al also reported that berberine inhibited murine melanoma B16 cell growth in vitro and in B16bearing nude mice (34). These data suggest that berberine could be an agent for treatment of many cancer cell types with micromole range concentration. 
A

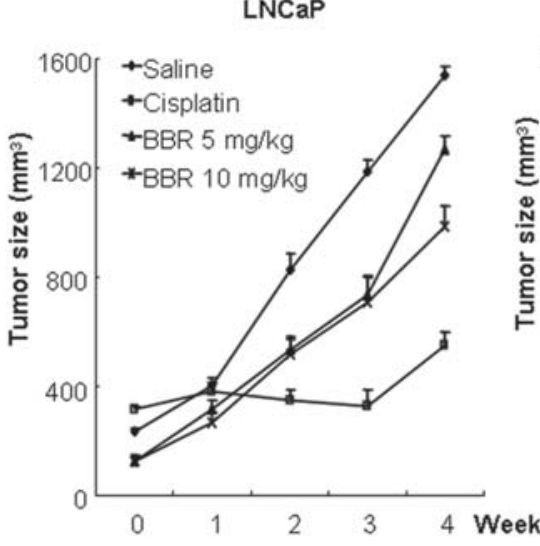

PC 3

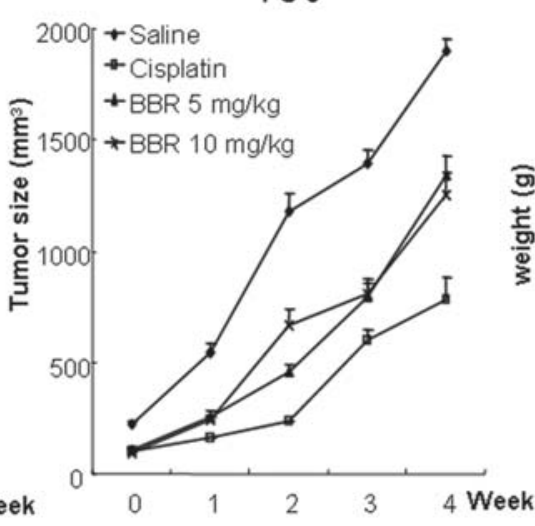

B

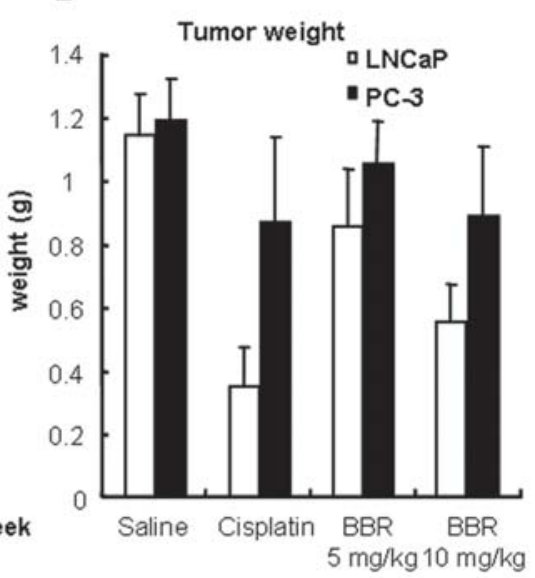

C

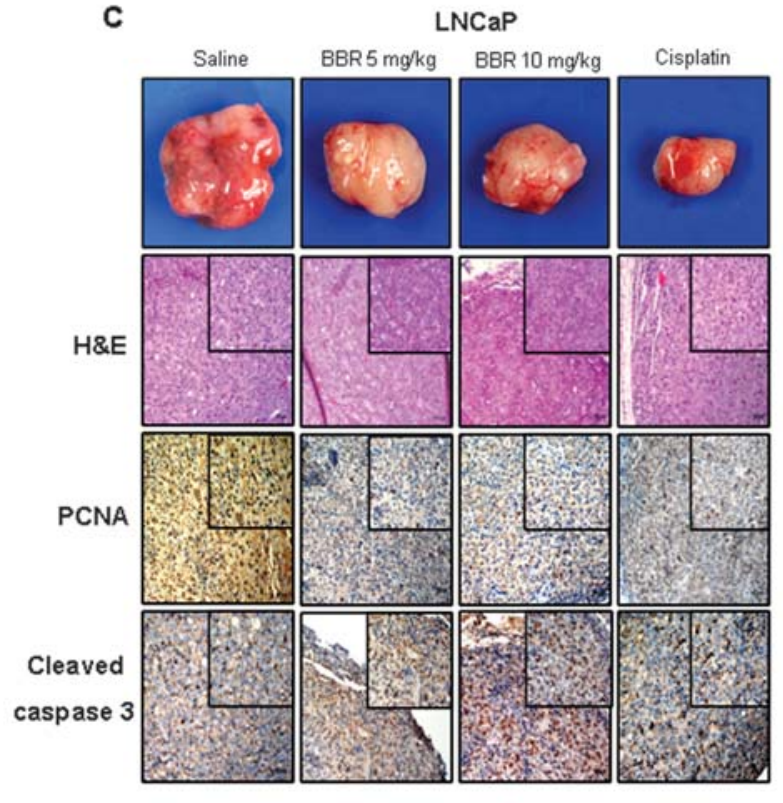

D

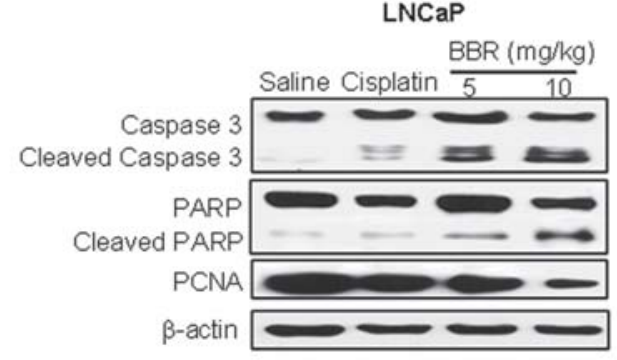

PC-3

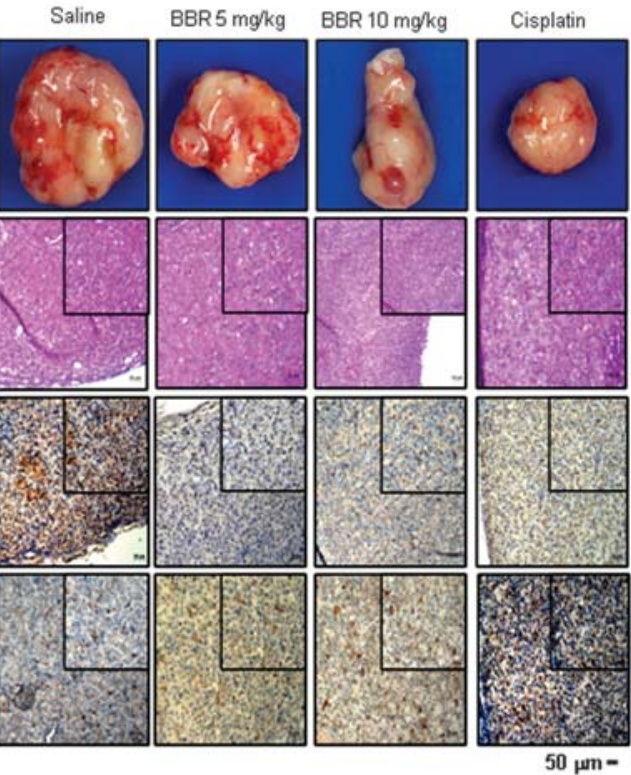

PC-3

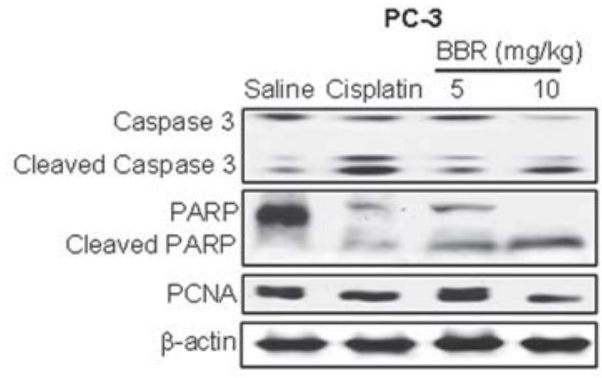

Figure 6. Anti-tumor activity of berberine in prostate cancer xenograft. Cells $\left(1 \times 10^{7}\right)$ were injected into the right lower flanks of nude mouse ( $\left.\mathrm{n}=10\right)$. Treatments were started on day 14 after tumor cell injection. Berberine was administered i.p. at 5 or $10 \mathrm{mg} / \mathrm{kg}$ twice per week for 4 weeks. At the end of the experiment, the animals were sacrificed and separated tumors. (A) Tumor burden was measured once per week using a caliper, and calculated volume [(width) $\left.)^{2} \mathrm{x}(\mathrm{length}) / 2\right]$. Tumor volume is presented as means \pm SD. (B) The tumor tissues were harvested at day 30 from the mice treated with or without berberine. The tumors were separated from the surrounding muscles and dermis, excised and weighed. Tumor weight is presented as means \pm SD. (C) Representative photographs of each group are shown at day 30 from the mice (upper panel). Lower panel represented microscopic images of tumor sections stained with H\&E, anti-proliferating cell nuclear antigen (PCNA), and anti-cleaved caspase-3 in xenograft tumors (magnification x100). (D) Combination of the three randomly selected tumor tissues each from ten individual mouse in control and berberine-treated groups were used for total cell lysate preparation and analyzed by Western immunoblotting for the expression of cleaved caspase-3, PCNA, and cleaved PARP as described in Materials and methods. Similar results were obtained in three independent experiments. Scale bar, $50 \mu \mathrm{m}$.

The most common anti-apoptotic lesion in cancers is the inactivation of p53 tumor-suppressor gene (17). It has been well established that p53 plays multiple tumor suppressive roles in cells upon introduction of stresses to regulate cell cycle $G_{1}$ and $G_{2}$ arrest or apoptosis, in part depending on the cell type (35). In most cases, induction of p53 leads to an 
irreversible inhibition of cancer cell growth, most decisively by activating the apoptosis pathway. Several naturallyoccurring anti-tumor agents have been shown to induce cell cycle arrest followed by apoptosis of cancer cells in a p53dependent manner such as human gastric cancer cell death by arsenic trioxide (36), bladder cancer T24 cell death by ellagic acid (37), lung cancer A549 cell death by plumbagin (38), and leukemia cell death by capsaicin (26). Moreover, p53-dependent apoptosis of cancer cells by berberine was also found in gastric carcinoma SNU-5 cell line (31). Therefore, it is possible that p53 pathway critically contributes to berberine-induced apoptotic cell death of prostate cancer cells. To delineate whether berberine-induced apoptosis in prostate cancer cells is p53-dependent or not, we compared cancer cell vulnerability against berberine in p53 expressing and lacking cells. Our present data showed that berberine inhibited cell growth in prostate cancer LNCaP (p53 wt) and PC-3 (p53 mutant) cells, however, the growth inhibitory effect of berberine is more effective in LNCaP cells. Subsequently, we also found that berberine increased the expression and translocation of $\mathrm{p} 53$ proteins into nucleus in $\mathrm{p} 53$ positive $\mathrm{LNCaP}$ cells in a concentration-dependent manner, but there was no change in mutant p53 expressing cell line PC-3. In addition, the inhibition of p53 by treatment with a p53 siRNA or a specific p53 inhibitor, PFT- $\alpha$, attenuated berberine-induced cell growth inhibition and induction of apoptosis in LNCaP cells. These data suggest that berberine-induced cancer cell growth and apoptotic cell death could be involved with the activation of p53 signaling pathway.

Molecular analyses of human cancers have revealed that cell cycle regulators are frequently involved in most of the common malignancies (39). Among them, p2 $1^{\mathrm{WAF} 1}$, a downstream target of p53, is critical in the regulation of cancer cell cycle. $\mathrm{p} 21^{\mathrm{WAF} 1}$ is an inhibitor of cyclin-dependent kinases 2, 4 and 6 and its upregulation causes the cells to undergo $G_{1}$ arrest. The present data showed that consistent with the greater effect on cell growth inhibition, berberine induced cell arrest in the $\mathrm{G}_{0} / \mathrm{G}_{1}$ phase of LNCaP cells that was much greater than that of PC-3. We also found that berberine increased p21 expression in LNCaP cells but it was not detected in PC-3 cells. In addition, remarkably greater changes of the expression of cell cycle-related proteins, cyclin $\mathrm{D} 1$, cyclin $\mathrm{E}, \mathrm{Cdk} 2$ and $\mathrm{Cdk} 4$ in $\mathrm{LNCaP}$ cells than that of PC-3 cells were also observed. These effects correlated well with the induction of apoptosis by berberine. That is, berberine more effective and significantly (2-fold higher) induced apoptosis in LNCaP cells compared to the effect in PC -3 cells. Activation of caspase- 3 (determined by the increase of the expression of cleaved caspase- 3 and PARP) was more increased in LNCaP cells. Furthermore, p53 siRNA and inhibitor of p53 reversed berberine-induced apoptosis of p53-positive cells as well as the p53-mediated apoptosis regulatory protein (caspase-3) expression. These data together suggest that p21-dependent cell cycle arrest followed by the activation of caspase- 3 may be critical in the p53-dependent berberine-induced apoptosis of prostate cancer cells. Caspase activation mechanism is involved in berberine-induced human epidermoid carcinoma A431 cells, prostate cancer cells, promonocytic U937 cancer cells, leukemia HL-60 cells, and human hepatoma cell death $(32,33,40-42)$. More recently, when we were preparing our study caspase- 3 activation was suggested as a critical cell death signal in prostate cancer cell death by berberine (33).

Our in vivo study with prostate xenograft-bearing nude mice following berberine treatment we found that intraperitoneal administration of berberine at a $10 \mathrm{mg} / \mathrm{kg}$ caused a substantial decline in tumor volume and weight of prostate cancer PC-3 and LNCaP xenograft, and that the extent of tumor growth inhibition by berberine was greater in $\mathrm{LNCaP}$ cells, suggesting that berberine more effectively inhibited p53 positive cancer cell growth. There is increasing evidence that p53 may directly regulate androgen signaling (25). The p53 protein has been shown to interact with several steroid receptors including the androgen receptor (AR) (43). LNCaP cells express AR, but PC-3 cells do not express AR. It is known that AR expression prostate cancer can be more susceptible for anti-cancer agents $(44,45)$. For example, lycopene differentially induced apoptosis at concentration $10 \mathrm{nM}$ in $\mathrm{LNCaP}$ cells and at concentration $1 \mu \mathrm{M}$ in PC- 3 cells. Thus, it is possible that berberine may be more effective in cancer cell growth in LNCaP cells expressing p53 as well as AR. To investigate whether berberine could be developed into an effective drug, we examined the absorption, distribution, metabolism, excretion and toxicity (ADME/Toxicity) using a prediction program (preADME version 1.0.2). Berberine has good oral and intestinal absorption as determined by the Caco- 2 and MDCK cell permeability assay, and was found to easily pass through the brain-blood barrier. Berberine was also evaluated not to be rodent carcinogenic. In conclusion, the present study demonstrated that berberine inhibited prostate cancer cell growth by affecting $G_{0} / G_{1}$ phase cell cycle arrest followed by apoptosis in a p53 signal-dependent manner, suggesting that berberine can be useful as an anti-cancer agent.

\section{Acknowledgements}

This work was supported by the Korea Science and Engineering Foundation (KOSEF) funded by the Korean Government (MOST) (R13-2008-001-00000-00).

\section{References}

1. Kelloff GJ, Crowell JA, Steele VE, et al: Progress in cancer chemoprevention: development of diet-derived chemopreventive agents. J Nutr 130: 467-471, 2000.

2. Ahmad N, Feyes DK, Nieminen AL, Agarwal R and Mukhtar H: Green tea constituent epigallocatechin-3-gallate and induction of apoptosis and cell cycle arrest in human carcinoma cells. J Natl Cancer Inst 89: 1881-1886, 1997.

3. Deigner HP and Kinscherf R: Modulating apoptosis: current applications and prospects for future drug development. Curr Med Chem 6: 399-414, 1999.

4. Buolamwini JK: Cell cycle molecular targets in novel anticancer drug discovery. Curr Pharm Des 6: 379-392, 2000.

5. McDonald ER and El-Deiry WS: Cell cycle control as a basis for cancer drug development. Int J Oncol 16: 871-886, 2000.

6. Takase H, Yamamoto K, Ito K and Yumioka E: Pharmacological studies on antidiarrheal effects of berberine and geranin herb. Nippon Yakurigaku Zasshi 2: 101-112, 1993.

7. Huang WM, Wu ZD and Gan YQ: Effects of berberine on ischemic ventricular arrhythmia. Zhonghua Xin Xue Guan Bing Za Zhi 5: 300-301, 1989

8. Kuo CL, Chi CW and Liu TY: The anti-inflammatory potential of berberine in vitro and in vivo. Cancer Lett 203: 127-137, 2004. 
9. Hano K: Pharmacological studies on metabolism of cancer tissues: pharmacological studies on carcinostatic effects of some plant components and their derivatives. Gann 48: 443-450, 1957.

10. Hoshi A, Ikekawa T, Ikeda Y, Shirakawa S and Iigo M: Antitumor activity of berberrubine derivatives. Gann 67: 321-325, 1976.

11. Fukuda K, Hibiya Y, Mutoh M, Koshiji M, Akao S and Fujiwara H: Inhibition by berberine of cyclooxygenase-2 transcriptional activity in human colon cancer cells. J Ethnopharmacol 2: 227-233, 1999.

12. Lin JG, Chung JG and Wu LT: Effects of berberine on arylamine $\mathrm{N}$-acetyltransferase activity in human colon tumor cells. Am J Chin Med 27: 265-275, 1999.

13. Mazzini S, Bellucci MC and Mondelli R: Mode of binding of the cytotoxic alkaloid berberine with the double helix oligonucleotide d(AAGAATTCTT)(2). Bioorg Med Chem 11: 505-514, 2003

14. Qin Y, Pang JY, Chen WH, Cai Z and Jiang ZH: Synthesis, DNA-binding affinities, and binding mode of berberine dimmers. Bioorg Med Chem 14: 25-32, 2006.

15. Tse WC and Boger DL: A fluorescent intercalator displacement assay for establishing DNA binding selectivity and affinity. Acc Chem Res 37: 61-69, 2004.

16. Liu LF: DNA topoisomerase poisons as antitumor drugs. Ann Rev Biochem 58: 351-375, 1989.

17. Hainaut P and Hollstein M: p53 and human cancer: the first ten thousand mutations. Adv Cancer Res 77: 81-137, 2000.

18. Vousden $\mathrm{KH}$ and Lu X: Live or let die: the cell's response p53. Nat Rev Cancer 2: 594-604, 2002.

19. Xiong Y, Hannon GJ, Zhang H, Casso D, Kobayashi R and Beach D: p21 is a universal inhibitor of cyclin kinases. Nature 366: 701-704, 1993.

20. Hoffman WH, Biade S, Zilfou JT, Chen J and Murphy M: Transcriptional repression of the anti-apoptotic survivin gene by wild-type p53. J Biol Chem 277: 3247-3257, 2002.

21. Olitvai ZN, Milliman CL and Korsmeyer SJ: Bcl-2 heterodimerizes in vivo with a conserved homolog, Bax, that accelerates programmed cell-death. Cell 74: 609-619, 1993.

22. Wang $X$ : The expanding role of mitochondria in apoptosis Genes Dev 15: 2922-2933, 2001.

23. Weir NM, Selvendiran K, Kutala VK, et al: Curcumin induces $\mathrm{G}(2) / \mathrm{M}$ arrest and apoptosis in cisplatin-resistant human ovarian cancer cells by modulating Akt and p38 MAPK. Cancer Bio Ther 6: 178-184, 2007.

24. Kuo PL, Chiang LC and Lin CC: Resveratrol-induced apoptosis is mediated by p53-dependent pathway in Hep G2 cells. Life Sci 72: 23-34, 2002

25. Hastak K, Gupta S, Ahmad N, Agarwal MK, Agarwal ML and Mukhtar H: Role of p53 and NF-kappaB in epigallocatechin3-gallate-induced apoptosis of LNCaP cells. Oncogene 22 : 4851-4859, 2003

26. Ito K, Nakazato T, Yamato K, et al: Induction of apoptosis in leukemic cells by homovanillic acid derivative, capsaicin, through oxidative stress: implication of phosphorylation of p53 at Ser-15 residue by reactive oxygen species. Cancer Res 64 . 1071-1078, 2004

27. Ahn KS, Park KS, Jung KM, et al: Inhibitory effect of glycolic acid on ultraviolet B-induced c-fos expression, AP-1 activation and p53-p21 response in a human keratinocyte cell line. Cancer Lett 186: 125-135, 2002.

28. Son DJ, Park MH, Chae SJ, et al: Inhibitory effect of snake venom toxin from Vipera lebetina turanica on hormonerefractory human prostate cancer cell growth: induction of apoptosis through inactivation of nuclear factor kappaB. Mol Cancer Ther 6: 675-683, 2007.
29. Levine AJ: p53, the cellular gatekeeper for growth and division. Cell 88: 323-331, 1997

30. Komarov PG, Komarova EA, Kondratov RV, Christov-Tselkov K, Coon JS, Chernov MV and Gudkov AV: A chemical inhibitor of p53 that protects mice from the side effects of cancer therapy. Science 285: 1733-1737, 1999.

31. Lin JP, Yang JS, Lee JH, Hsieh WT and Chung JG: Berberine induces cell cycle arrest and apoptosis in human gastric carcinoma SNU-5 cell line. World J Gastroenterol 12: 21-28, 2006.

32. Mantena SK, Sharma SD and Katiyar SK: Berberine inhibits growth, induces G1 arrest and apoptosis in human epidermoid carcinoma A431 cells by regulating Cdki-Cdk-cyclin cascade, disruption of mitochondrial membrane potential and cleavage of caspase-3 and PARP. Carcinogenesis 27: 2018-2027, 2006.

33. Mantena SK, Sharma SD and Katiyar SK: Berberine, a natural product, induces G1-phase cell cycle arrest and caspase-3dependent apoptosis in human prostate carcinoma cells. Mol Cancer Ther 5: 296-308, 2006.

34. Letasiova S, Jantova S, Muckova M, et al: Antiproliferative activity of berberine in vitro and in vivo. Biomed Pap Med Fac Univ Palacky Olomouc Czech Repub 149: 461-463, 2005.

35. Kastan MB, Canman CE and Leonard CJ: P53, cell cycle control and apoptosis: implications for cancer. Cancer Metastasis Rev 14: 3-15, 1995.

36. Jiang XH, Wong BC, Yuen St, et al: Arsenic trioxide induces apoptosis in human gastric cancer cells through up-regulation of p53 and activation of caspase-3. Int J Cancer 91: 173-179, 2001.

37. Li TM, Chen GW, Su CC, Lin JG, Yeh CC, Cheng KC and Chung JG: Ellagic acid induced p53/p21 expression, G1 arrest and apoptosis in human bladder cancer T24 cells. Anticancer Res 25: 971-979, 2005.

38. Hsu YL, Cho CY, Kuo PL, Huang YT and Lin CC: Plumbagin (5-hydroxy-2-methyl-1,4-naphthoquinone) induces apoptosis and cell cycle arrest in A549 cells through p53 accumulation via c-Jun NH2-terminal kinase-mediated phosphorylation at serine 15 in vitro and in vivo. J Pharmacol Exp Ther 318: 484-494, 2006.

39. Molinari M: Cell cycle checkpoints and their inactivation in human cancer. Cell Prolif 33: 261-274, 2000.

40. Jantova S, Cipak L and Letasiova S: Berberine induces apoptosis through a mitochondrial/caspase pathway in human promonocytic U937 cells. Toxicol In Vitro 21: 25-31, 2007.

41. Lin CC, Kao ST, Chen GW, Ho HC and Chung JG: Apoptosis of human leukemia HL-60 cells and murine leukemia WEHI-3 cells induced by berberine through the activation of caspase- 3 . Anticancer Res 26: 227-242, 2006.

42. Hwang JM, Kuo HC, Tseng TH, Liu JY and Chu CY: Berberine induces apoptosis through a mitochondria/caspases pathway in human hepatoma cells. Arch Toxicol 80: 62-73, 2006.

43. Gleave M, Goldenberg SL, Bruchovsky N and Rennie P: Intermittent androgen suppression for prostate cancer: rationale and clinical experience. Prostate Cancer Prostatic Dis 1: 289-296, 1998.

44. Ivanov NI, Cowell SP, Brown P, Rennie PS, Guns ES and Cox ME: Lycopene differentially induces quiescence and apoptosis in androgen-responsive and -independent prostate cancer cell lines. Clin Nutr 26: 252-263, 2007.

45. Maria McCrohan A, Morrissey C, O'Keane C, et al: Effects of the dual 5 alpha-reductase inhibitor dutasteride on apoptosis in primary cultures of prostate cancer epithelial cells and cell lines. Cancer 106: 2743-2752, 2006. 